\title{
California's growing diversity drives profound change
}

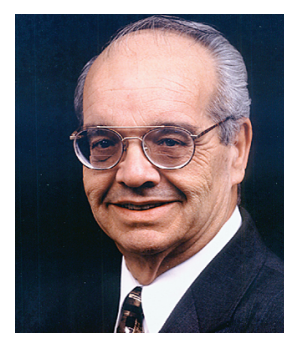

W. R. Gomes

Vice President,

Agriculture and
Natural Resources

$\Lambda^{s}$ the 2000 census confirmed, California has become a multicultural society with no single ethnic majority. Today, our 35.5 million diverse citizens are $46 \%$ non-Latino white, 35\% Latino, $12 \%$ Asian and $6 \%$ black. This historic shift is the leading edge of a massive demographic change. By 2030, Latinos are projected to make up almost $44 \%$ of California's population - 22.6 million people. Asians and Latinos together will comprise more than two-thirds of the state's citizens.

The dramatic and continuous growth of Latinos and other ethnic groups (see California Agriculture, January-

February 2000) means that UC's Division of Agriculture and Natural Resources (ANR) needs to develop new and more effective ways to reach its diverse clientele. Fully $40 \%$ of Californians speak languages other than English at home; Spanish is our second most common language, used by $26 \%$.

California's ethnically diverse groups may be new to the state and nation, and often have the most critical need for the information ANR has to offer. Our faculty, advisors and staff have the new challenge of delivering this research in ways that can be understood linguistically and culturally.

This issue of California Agriculture contains five articles that illustrate how ANR researchers and educators are serving a diversity of Californians. Researchers investigate Latino food insecurity (page 18), shed light on the puzzling coexistence of hunger and obesity (page 12), report on why a large number of eligible rural Latino families fail to claim the Earned Income Tax Credit (page 24), examine how Proposition 10 funds are distributed to improve the health and education of preschool children (page 27) and analyze farmworker employment patterns statewide (page 35).

These studies represent but a small fraction of efforts under way to extend UC research results to Californians in every corner of the state. ANR information spans the full range of agricultural, natural and human resource issues facing the state, including nutrition, food safety, specialty crop production, water and soil conservation, pesticide handling, household budgeting, parenting - even responses to a natural disaster (page 6). It is delivered through Cooperative Extension county offices statewide.

Bilingual ANR researchers and educators help us better meet the needs of our diverse clientele. Today nearly 60 Cooperative Extension advisors (about one in four) speak Spanish fluently, and more than 40 county offices have at least one advisor or staff person who speaks Spanish. Virtually every major program in ANR now has materials available in Spanish, as well as Hmong, Laotian, Vietnamese and Japanese. Other statewide efforts include:

Pesticide safety. Since 1992, the IPM Pesticide Safety Education program has conducted nearly 300 workshops to train and certify more than 4,800 instructors in the safe use of pes- ticides. These instructors in turn have trained over 870,000 farmworkers, growers and pesticide handlers, most of them Spanish-speaking, in pesticide handling, interpretation of label information and field application. The bilingual Illustrated Guide to Pesticide Safety/Guia Ilustrada para el Uso Seguro de Pesticidas has sold more than 100,000 copies.

Multilingual outreach. ANR's Spanish Broadcast and Media Services and Communication Services help extend science-based information to clientele in Spanish and other languages through translation services, news releases, radio feeds and preparation of reports and other publications.

Small farms. The UC Small Farm Program has six bilingual farm advisors working with growers in Spanish, English and Southeast Asian languages. Conferences and field days have been conducted entirely in Spanish, and many written materials, compact disks and audiotapes on specialty crops, production and marketing practices, are available in Spanish and other languages. Pesticide safety manuals have also been translated into Korean and Ilocano.

Farm safety. The Farm Safety program and the UC Agricultural Ergonomics Research Center develop innovative practices and equipment to reduce the historically high rates of farm injuries. The program produces educational materials in Spanish and English on ergonomic risk factors, develops specific interventions, demonstrates them and trains workers in the field. One such intervention involved the development of reduced tub sizes for wine-grape harvest, leading to a five-fold reduction in reported back pain without reducing productivity on farms adopting their use.

Nutrition education. The Food Stamp Nutrition Education Program (FSNEP) and the Expanded Food and Nutrition Education Program managed by ANR help clients to make more informed food-buying decisions and to be smarter consumers. The FSNEP program of California provided nutrition education to 127,800 families in 2002-2003; of these, $44.6 \%$ were Latino.

Accomplishments like these were considered innovative and groundbreaking 10 years ago; today they are the expectation. The Division strives to keep current, even one step ahead, of the educational and technical assistance needs of California's multicultural society. We have been successful because our scientists, advisors and staff are trusted sources of unbiased, research-based information, and because we are organized to deliver research results and practical information to stakeholders in every community in the state. No other UC program can make this claim.

However, the current budget crisis, and deep funding cuts to UC Cooperative Extension and the Agricultural Experiment Station, present serious challenges for the future.

These and other programs enable the University to meet a vital land-grant responsibility. They address the diverse needs of Californians, providing them with science-based knowledge for the safe and viable production of food, forests and fiber, and augmenting the health, economy and environmental well-being of the state. 